\title{
Fighting hospital malnutrition: let's start by calibrating hospital scales!
}

\author{
Carlo Pedrolli $\cdot$ Emanuele Cereda $\cdot$ Antonio Costa
}

Received: 4 November 2008 / Accepted: 31 March 2009 / Published online: 22 May 2009

(C) Springer-Verlag 2009

\begin{abstract}
Body weight measurement is fundamental in nutritional screening. Thus, weighing scales should be regularly calibrated. This procedure is so important that in 1990 the Council of Europe produced an ad hoc directive. Unfortunately, little is known about scales management in hospitals. We performed an inventory in the City Hospital of Trento ( $~ 900$ beds), which is responsible for the healthcare of $\sim 250,000$ inhabitants. The analysis included flat, chair and paediatric neonatal scales. We focused attention on the date of arrival and calibration management. In the hospital, there were 211 scales: 190 flat scales, 13 chair scales and 8 paediatric neonatal scales. The mean "age" was $10.3 \pm 7.3$ years; $22.3 \%$ were $5-10$ years old and $44.1 \%$ were aged $>10$ years. No scale was ever calibrated. They are managed by the "Internal Logistics Unit", meaning that scales are regarded as pieces of furniture rather than as diagnostic tools.
\end{abstract}

Statement of authorship All the authors significantly contributed to the work, and read and approved the final manuscript. Particularly, E.C. and C.P. designed the study. C.P. collected the data. E.C. analysed the data and wrote the manuscript. A.C. significantly contributed to critical revision of the article. All the Authors read and approved the final version of the manuscript for submission.

C. Pedrolli · A. Costa

Dietetic and Clinical Nutrition Unit

Trento Hospital

Trento, Italy

E. Cereda (西)

International Center for the Assessment

of Nutritional Status (ICANS)

University of Milan

Via Botticelli 21, 20133 Milan, Italy

e-mail: emanuele.cereda@virgilio.it
Accurate weight measurement is a key task in nutritional management. However, our results once highlight limitations in this process. It is not enough to design laws and accreditation standards for the European Community; enforcement should be also checked.

Keywords Hospital malnutrition · Nutritional assessment · Weighing scales $\cdot$ Scales calibration $\cdot$ Health policies

There is no doubt that hospital malnutrition is one of the biggest international health scandals. It has been studied worldwide [1, 2] and despite increasing awareness it still goes undiagnosed and undertreated [3]. It seems that clinicians are much more interested in describing the dimension of the problem than in coping with it. Along with this, recent studies focusing on current clinical practice point out poor nutritional routines and attitudes among healthcare professionals [3, 4].

We think that hospital malnutrition must be tackled, even with small interventions that, one by one, allow modification of current practices. This was the objective of our recent discussion on the possible role of the catering service in hospital nutrition management $[5,6]$.

In practice, nutritional risk screening is fundamental and body weight is the most frequently used parameter, not only per se through body mass index and weight loss calculation [7], but also within simplified screening tools $[8,9]$. In this regard, a key task is to have scales regularly calibrated. This procedure is thought so important that in 1990 the Council of Europe produced an explicit ad hoc directive [10] that was not acknowledged by the Italian Government until 1994. Thus, instruments should theoretically undergo, as a standard for hospital accreditation, periodical calibration [11]. 
Little is known about current practices in relation to management of weighing scales in hospitals. Accordingly, we tried to provide a contribution based on the experience at our hospital. Our aims were: (1) to find out how many weighing scales were present in the hospital; (2) establish the date of their arrival; and (3) find out if they have been calibrated periodically.

The study was performed at the City Hospital of Trento, in the northern Italian Region of Trentino-Alto Adige. This is a non-university hospital with $\sim 900$ beds, which accounts for the healthcare of $\sim 250,000$ ( 110,000 in the city and 140,000 outside the city) inhabitants. In the hospital, there are 5 intensive care units, 11 units belonging to the surgical ward, 16 units belonging to the medical ward and 16 units for diagnosis and cure (ambulatory and day hospital). Our inventory included flat, chair and paediatric neonatal scales; the inventory was provided by a register held by the administration of hospital. Weighing beds were not included in the analysis.

A summary of the scales inventory is presented in Table 1 . In the hospital, there were 211 scales: 190 flat

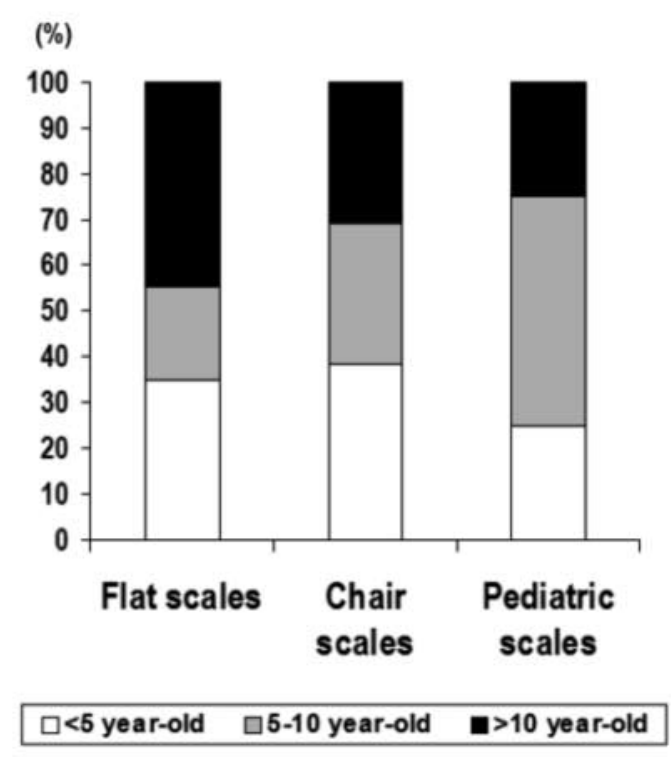

Fig. 1 Age of scales (prevalence of every type) scales $(90.0 \%), 36$ with stadiometer, 13 (6.2\%) chair scales and $8(3.8 \%)$ paediatric neonatal scales. The mean overall "age" was $10.3 \pm 7.3$ years. Interestingly, $22.3 \%$ $(n=47)$ were 5-10 years old, while $44.1 \%(n=93)$ were more than 10 years old (Fig. 1). The scales were all in use and were located in very different rooms of single units ranging from ambulatories to corridors to ward sisters' rooms. None of the scales had ever been calibrated. This was confirmed by both hospital management and the Regional Metric Engineer, who, as the only person responsible for the checking of all the scales in the Province of Trento, confirmed he had never been called to Trento Hospital. Weighing scales our hospital are managed by the "Internal Logistics Unit".

It seems quite strange to talk about hospital scales when weight, BMI and weight loss are advocated as major determinants of nutritional risk and outcome in the whole population (adult and elderly) $[1,7,8]$. The standard at our hospital is to weight in-patients on referral but an ongoing survey is checking the way this standard is accomplished. However, the results of our inventory are astonishing. We found that at least two thirds of the scales are more than 5 years old and none of them have ever been calibrated. This was so not only for adult scales but also for neonatal/paediatric scales, in which the lack of accuracy is even more unacceptable, particularly considering recent reports on the prevalence of malnutrition in both paediatric and neonatal cases $[12,13]$. In this regard, we found an astonishing explanation. In our hospital, scales are managed by the Internal Logistics Unit, which mainly deals with furniture, cleaning, laundry and so on, rather than to Clinical Engineering, which deals with the technical management of medical instruments and is usually responsible for contacting the competent expert (Regional Metric Engineer). This means that scales are regarded as an element of furnishing of our wards rather than a diagnostic tool.

It might be interesting to check the accuracy of a randomised sample of these scales and to see if biases become larger with age. Unfortunately, due to the aforementioned improper management of the calibration procedure, this was not possible.

Table 1 Inventory of hospital weighing scales

\begin{tabular}{llll}
\hline & $\begin{array}{l}\text { Overall } \\
(n=211)\end{array}$ & $\begin{array}{l}\text { Flat } \\
(n=190)\end{array}$ & $\begin{array}{l}\text { Chair } \\
(n=13) \\
(n=8)\end{array}$ \\
\hline Mechanical, $n$ & 197 & 184 & 11 \\
Electronic, $n$ & 14 & 6 & 2 \\
Age, years & $10.3 \pm 7.3$ & $11.4 \pm 7.4$ & $6.5 \pm 5.5$ \\
$5-10$ years old, $n(\%)$ & $47(22.3)$ & $9(20.5)$ & $4(30.8)$ \\
$>10$ years old, $n(\%)$ & $93(44.1)$ & $85(44.7)$ & $4(30.8)$ \\
Recently calibrated, $n(\%)$ & None & None & None \\
Never calibrated, $n(\%)$ & All & All & $4.1 \pm 2.2$ \\
\hline
\end{tabular}

aMean \pm standard deviation 
In matters of nutrition, accurate measurement of body weight is a key task, not only on hospital admission but also during the stay and at discharge, as it allows guidance in nutritional support and monitoring of its efficacy (e.g., in a course of refeeding) as well as that of other treatments (e.g., dialysis). We do not know what the situation is in the rest of Europe but have learnt that it is not enough to design laws and accreditation standards for the European Community if enforcement is not checked. Despite consistent awareness of the malnutrition problem [1], the performance (nutritional assessment and intervention) of the healthcare professionals is still poor and our results emphasize this [3,4]. Accordingly, practices still need to be improved and it would probably be of interest to check calibration procedure standards in every hospital in order to avoid potential biases in weighing patients accurately.

Conflict of interest The Authors certify that there are no affiliations with or involvement in any organisation or entity with a direct financial interest in the subject matter or materials discussed in the manuscript.

\section{References}

1. Norman K, Pichard C, Lochs H et al (2008) Prognostic impact of disease-related malnutrition. Clin Nutr 27:5-15

2. Waitzberg DL, Caiaffa WT, Correia MI (2001) Hospital malnutrition: the Brazilian national survey (IBRANUTRI): a study of
4000 patients. Nutrition 17:573-580

3. Bavelaar JW, Otter CD, van Bodegraven AA et al (2008) Diagnosis and treatment of (disease-related) in-hospital malnutrition: the performance of medical and nursing staff. Clin Nutr 27:431-438

4. Singh H, Watt K, Veitch R et al (2006) Malnutrition is prevalent in hospitalized medical patients: are house staff identifying the malnourished patient? Nutrition 22:350-354

5. Pedrolli C, Cereda E (2008) Facing hospital malnutrition: when will we understand that a precious ally lies in our catering service leading Chef? Clin Nutr 27:479-480

6. Cereda E, Pedrolli C (2009) Way of delivering food in hospital to improve nutrition. Clin Nutr 28:105

7. Izawa S, Enoki H, Hirakawa $\mathrm{Y}$ et al (2007) Lack of body weight measurement is associated with mortality and hospitalization in community-dwelling frail elderly. Clin Nutr 26:764-770

8. Kondrup J, Allison SP, Elia M et al; Educational and Clinical Practice Committee, European Society of Parenteral and Enteral Nutrition (ESPEN) (2003) ESPEN guidelines for nutrition screening 2002. Clin Nutr 22:415-421

9. Cereda E, Limonta D, Pusani C et al (2006) Assessing elderly at risk of malnutrition: the new Geriatric Nutritional Risk Index versus Nutritional Risk Index. Nutrition 22:680-682

10. European Commission (1990) Council Directive 90/384/EEC of 20 June 1990 on the harmonization of the laws of the Member States relating to non-automatic weighing instruments. Official Journal 189, 20/07/1990, pp 1-16

11. Joint Commission International (2008) Joint Commission International Accreditation Standards for Hospitals, 3rd Edn. Joint Commission Resources

12. Grover A, Khashu M, Mukherjee A et al (2008) Iatrogenic malnutrition in neonatal intensive care units: urgent need to modify practice. JPEN J Parenter Enteral Nutr 32:140-144

13. Pawellek I, Dokoupil K, Koletzko B (2008) Prevalence of malnutrition in paediatric hospital patients. Clin Nutr 27:72-76 